PARTE III 



\section{Testimonio en una memoria reposicionante, del dolor a la supervivencia}

\section{Sujeción al daño, el duelo en un exilio nómada}

Como se ha señalado en la introducción, es una labor importante para el académico y el intelectual estratégico dar cuenta de tres elementos: de la conceptualización, de la apuesta metodológica o práctica y de la expresión de subjetividad que movilizan las anteriores. Por lo cual prosigue en este apartado la exposición de una resignificación del daño como consecuencia de una experiencia de exilio nómada.

Terror: primera semana, acontece la amenaza que busca romper tu voluntad; y te hablan los comunicados, las advertencias, la recapitulación de los seguimientos de entes siniestros, la sumatoria de los efectos de amenazas pasadas, los mensajes cifrados de los funcionarios, las versiones contrarias de los que se dicen cercanos en el mundo de los pares, las injurias entre unos y otros bajo el velo de la diplomacia. Y especialmente te habla el miedo a morir, a morir uno con sus apuestas, a que sean muertos los de uno, los propios, los que nos son más cercanos al corazón. Toda su labor consiste en una sola misión: quebrar tu voluntad.

Fortaleza inicial: -resistencia y negación- desde la amarga salida del aeropuerto de la capital hasta la liviana llegada a una hospitalaria ciudad con buen aire, se levanta durante el primer mes, y se activa en lo más interior 
frente a ese poder del miedo, que te doblega e inactiva -que te siembra con piernas tembleques en un retrete con el estómago flojo-, se activa, la reacción de asumir con fuerza lo que había pasado y lo que ha llegado, buscas tener valentía llamando desde lo más íntimo la protección de tu potencia divina para no desfallecer.

En su primera expresión, esta fuerza dolida busca retomar el rumbo que se traía, como un efecto de la inercia existencial del proyecto de vida, así, hay que hacerse el imperturbable y continuar con los planes que se traían desde antes, este fue el intento fallido - pero paso obligado y necesario-de realizar lo que en uno viene de atrás hacia adelante, así quería realizar en un lugar sin arraigo ni reconocimiento lo que hacía en el propio con raíces profundas de más de treinta años. La idea de fondo parecía ser para entonces, demostrarse que ese golpe no había podido desfigurar o deformar lo que era o había sido.

Dolor: llegados al nuevo espacio, al nuevo hábitat arrendado "temporalmente propio" con los pocos ahorros que quedaron, en medio del acosador e incesante sonido de la demolición del edificio que había allí atrás de la habitación en que dormíamos, y abrigados por un permanente frío de invierno que no habíamos conocido en el trópico, emergió la sensación del cansancio, la que vino acompañada por los permanentes y repetidos sueños nocturnos de un naufragio en el que el enorme mástil -del barco en que viajaba- se partía en medio de la tormenta, el cuerpo del barco era roto por la furia de las olas marinas... no necesitaba demasiada psicología o interpretación de los sueños para saber que el barco era mi cuerpo, mi hábitat, mi alma, mi vida. 
Figura 34.

Soy capitan en la tormenta. Dibujo. Carlos Mario Arango. 2016

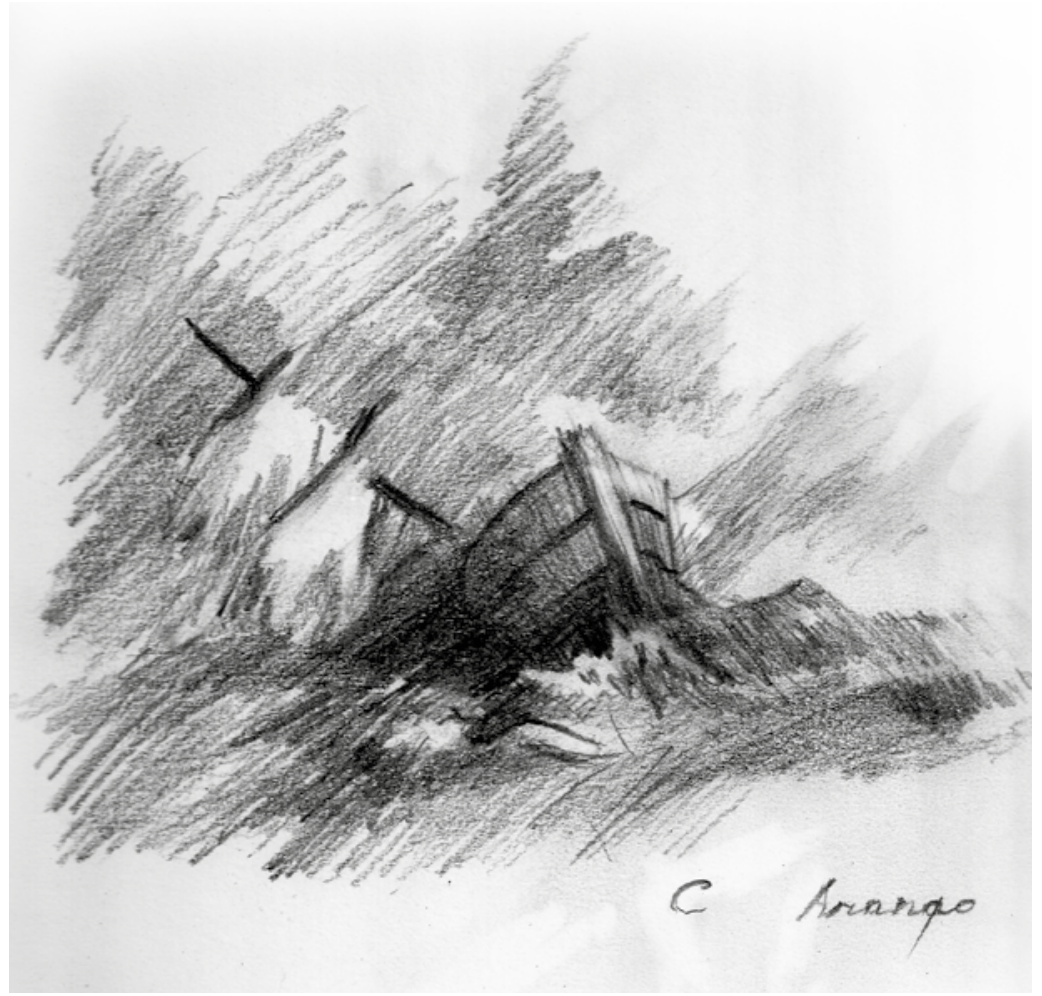

El hogar: ya que toda llegada a una casa trae consigo la posibilidad de la intimidad y del descanso, sucede que el hogar habitado activó el hogar interior, la casa se hizo arquetipo de reposo y ayudó a que en este descansar se dejara venir, caer y soltar lo que estaba contenido... ya en casa y por la pausa pude sentir la tormenta del dolor por la pérdida del mundo construído (qué sucede a quienes no tienen la oportunidad de la pausa para el dolor, me preguntaba).

Entonces, en medio de la tormenta emerge el dolor como riachuelo de llantos que con los días llenan e inundan los lagos del alma, lavando los restos de la avalancha con aguas de espíritu cristalino, las lágrimas indignadas venían y traían los bálsamos que desocupaban lentamente el sufrir, el padecer que produce el estoico acto de sí mismo de estar frente a la pérdida de lo cotidiano: el vínculo con lo más 
preciado, con lo familiar, - los amigos, los animales, los estudiantes, los libros-, y los espacios confortables, la pérdida de los árboles recién sembrados, del aire de la montaña, del sonido del riachuelo, la presencia tenue y silenciosa de los vecinos, y la familiaridad, incluso de las acostumbradas malas noticias del día a día... Este segundo y tercer mes había traído la descarga del llanto.

El abandono: a la par de este segundo y tercer mes se cobijó la semilla de la indignación por la poca solidaridad, no de los amigos, sino de la institucionalidad universitaria, de las ONG, de la gubernamentalidad nacional e internacional, ese precio que debes pagar cuando decides hablar y actuar por los DDHH sin alinearte a un partido, a un grupo de interés, a una élite; la universidad limitada a respuestas formales desde presupuestos ideales y funcionales -su máxima se hace trizas ante tu corazón "La universidad es campo de convivencia...y blablablá..." y ves allí que la gubernamentalidad se afana por restablecer la ficción de la sensación de tranquilidad general negando las situaciones particulares y específicas, los casos individuales bajo el epitome de "son casos aislados y blablablá;" y allí viví la recepción de las entidades internacionales que solo nos dieron información sobre procedimientos burocráticos que a lo único que conducían era a ser victimizado por la inatención "humanitaria", todo porque nos vieron "bien vestidos".

La ruptura: los estudiantes a quienes les compartía diálogo en clase también estaban muertos de miedo y plagados por la sanguijuela de la sospecha, miedo a que les sucediera lo mismo, y contagiados de dudas pensaban "si lo amenazaron fue por algo!...o las debía!” A los profesores “compañeros” les sucedía lo mismo... así viví en carne propia cómo los desplazados y exiliados padecen una suerte de enfermedad contagiosa que rompe el vínculo social: la desconfianza, el prejuicio, la acusación imaginaria o rumoreada.Veía a los académicos como ventrílocuos repetidores de discursos acostumbrados a hacer fila para esperar su jubilación... de todo esto... -lo único que pudo fortalecerme fue la filiación de los amigos, sus fuertes palabras de aliento. ( A Ah! Y no faltaría el cínico que diga que la ayuda y esfuerzo de amigos individuales cubre y equivale al de las instituciones...y blablablá... ¿Que si hay ropa, amigos y tejido de apoyo no requieres que te apoye ni que responda el Estado!) 
Tristeza-pérdida de la fuerza-: sí... sentí y siento tristeza por lo que no ha sido mi país, que mirado ante los ideales de la cultura o las románticas utopías personales es un país que desgasta y pierde su oportunidad en el planeta; que mal gasta y arruina la vida de sus pobladores en un conflicto sin salidas reales, que a los niños les enseña a tener miedo desde que nacen para que luego aprendan a reaccionar con agresión como forma de defensa... un país que para descansar de esto recurre a la fiesta, rumba y farra de fin de semana como salida en falso a través de la cual se descargan las frustraciones por medio de más violencia; a tal punto que se autodenomina "El país más feliz del mundo".

Odio: entonces todo se sumó y sentí el odio contra los desconocidos autores de dicha amenaza, un odio inespecífico porque no sabía ni llegué a saber quiénes lo hicieron; nada más y nada menos deseable, completamente comprensible, me decían mis amigos, odiar a los agentes de este tipo de infamia, de amenazas, imaginar su destrucción de mil maneras posibles; imaginaba buscar y revelar su identidad, ponerlos en la dimensión pública para acabar con su reputación. Idear protestas-performance e instalaciones-, cartas en los medios, métodos de denuncia y complots para que chocaran entre ellos, personajes imaginarios ... Sin embargo, pude percatarme que hacer cualquier cosa para saber quiénes fueron y actuar en su contra sería caer en su especularidad, en su juego, sería convertirme en uno de ellos, caer en la dinámica persecutoria que promueve el circulo victimario-víctima-vengador.

Decepción: .... me pregunté al menos por un par de años para qué creer en una sociedad en la cual no hay lealtades, en la que solo ELLA tiene una, con el dinero, con la codicia y otra con la pereza y la indiferencia. Llegué a creer que esta es una sociedad por la cual no vale la pena dar una lucha en el campo vital ni político -campo de las ideas y de las acciones-... puesto que sentí y con causa, la existencia de una especie de "presidente sombra" -una condición de muerte en vida de las masas por la indolencia, por su renuncia a un mundo mejor-.

Exploración del enemigo imaginado: nuevas formas de consecución de recursos aprovechando la ayuda y la astucia del mal colombiano pasaron por mi mente, me preguntaba, bordeaba la idea ¿Qué tal sería convertirse en uno de los colombianos codiciosos, en un traqueto, en 
un narco, en un político corrupto? Uno de todos los que ya sabemos que abusa de la riqueza geográfica y geoestratégica de este país, uno de esos que sabe aprovechar las condiciones, los lugares donde no ha llegado aún el Estado.

Con-fusión, exiliado o nómada: los procesos que hacemos al explorar nuevas geografías como desplazados (desterrado es la palabra correcta que por un neologismo de la Justicia Transicional institucional y una inadecuada política teórica se filtra para disminuir el impacto del crimen, tal como falso positivo lo hace para sustituir el de ejecución extrajudicial, que a su vez desplaza la realidad de un crimen innombrable: la legitimación privada y extralegal de la pena de muerte) o como exiliados, pueden sustituir las nuevas geografías psíquicas: llegar a un nuevo pueblo, a una ciudad, implica por obligación e inherencia de la situación, abrir nuevas puertas, caminos, espacios, horizontes; pero tener ante los ojos y para sí un abanico de posibilidades, por momentos confunde el alma, estar de frente a una libertad impuesta, tener el albedrío de volver a comenzar sin estar preparado para ello, confunde.

Esa confusión te detiene por el miedo a acertar o a equivocarte, crea una sensación de parálisis en el tiempo, quietud, de estacionamiento y de pérdida de dirección, pero el buen sentido y el sentido común -aunque otros crean que uno lo pierde-, el sentido del corazón sigue en pie, y dejarse guiar por él es una buena opción. Ver los caminos y nuevas opciones implica responder a la pregunta, en cada caso: ¿qué estoy dispuesto a perder y qué a ganar en cada una de estas rutas? Renunciar a los proyectos del pasado y aceptar la pregunta: ¿en qué me podré transformar desde hoy en cada camino?

Nostalgia: tanto por el modo de vida que se ha perdido, como por no poder estar con aquellas vivencias y sensaciones, o por no poder desarrollar ese futuro interior que una vez se vio posible, que allí en el lugar de origen se abría. Con el cambio de escenario es inevitablemente un cambio de vida y de mentalidad, una nueva forma de abordar la realidad, de resolver los problemas, de seguir hacia adelante, de no atorarse en los duelos y las rabias del pasado (sin ignorarlas), el mundo nuevo es de todas maneras una forma que hace añorar lo que en el otro espacio pudo ser y no será. 
Desolación: a esta nostalgia se suma ampliar la conciencia política, la conciencia sobre las miserias humanas y sobre nuestras propuestas para afrontarlas, se añade el reconocimiento de que nuestros problemas se deben a una falta de formación ética frente a la codicia, a la inexistencia de una lealtad espiritual y de una ilustración en la pluralidad; en especial por saber que quienes detentan poder no han entrado aún en el universo de la política, ya que confunden o hacen de la tiranía de la posesión su política social.

Indolencia- tocar fondo en la indiferencia: también pensé que estaba derrotado; y mi último grito interior contenía la misma traición que he criticado: "hay que unirse a ellos", a los indiferentes, y hacer como si nada ocurriera, ser igualmente indolente. Así recuerdo que me sorprendía por la manera en que en los días de amenazas a estudiantes y docentes, los llamados "académicos" abandonaban las aulas, las bibliotecas y su tiempo de escribir para reunirse en muchedumbre a ver la final de la "Champions League" del año 2006 entre el Barcelona y su contendor inglés... Liverpool.

En efecto, perdí la fuerza, llegué a pensar que unírmeles sería una buena estrategia para mitigar o distraer la soledad -si hablar de la realidad les fastidia, y si les encanta la "realidad" del espectáculo, diseñada por los de/formadores de mentes-, si gusta más el confort que los derechos, negar la realidad sería una buena opción, unirse a su matriz-matrix. No hablar de los victimarios de las extremas y de sus víctimas. De los diputados y sus familias, de los policías y sus familias, de los olvidados e ignorados y sus familias... de los combatientes y sus familias; no hay que hablar de todos con los que jugaron, juegan y jugaran los ilegales y los "legales" del poder, etc.... Empecé a guardar silencio... y sé, que por un momento fui vencido por quienes activaron esta máquina de exilio, máquina de viaje en el tiempo y el espacio, que al traerme de nuevo al punto de partida me enseñó que la mejor forma de "convivir" en este país es unirse a la banda de la indolencia por medio de la indiferencia. En ese momento, tres años después de los hechos lograron su propósito.

Ellos, los indiferentes, no quieren aprender a vivir en el mundo de la política sino acomodarse en el mundo de las dictaduras del poder, que suenan a democraduras, partidocracias, partidoduras, donde su 
única apuesta es la que nace de su empuje-ambición por la posesión y el control de su statu quo.

Estado de vencido-Neofobia: ahora tengo aprehensión por el futuro, reconozco en mí, miedo al cambio, miedo a lo nuevo, miedo a la libertad impuesta por lo habitual; justifico mi manía y depresión en la búsqueda de un hedonismo superfluo y cotidiano; ahora soy como ellos, un habitante "feliz".

Fue así como toqué fondo, tomando conciencia de este recorrido doliente por medio de los cambios de las emociones y motivaciones que activaron mis decisiones.

\section{Transformaciones del ser: reposicionarse}

Desgarramiento: si los efectos del exilio, como dice Toni Negri, se escriben con $\mathrm{D}$ de desgarro, de decepción... las luchas se escriben con $\mathrm{R}$ de resistencia, renuncias, renegaciones, recordaciones, reconocimientos, re-creaciones para poder alcanzar nuestras afirmaciones internas más altas y elevadas, nuestra propiedad en la cima del alma que se acerca a la creación del propio Dios, de los ideales comunitarios más nobles, poliformes, móviles y vitales.

Poder r-enunciar: a veces es bueno renunciar a una lucha, esa lucha política que damos desde la micropolítica -con los cercanos, que la mayor de las veces no nos entienden-, así, con moderación debemos aprender a reconocer cuáles luchas dar y cuáles no, y en dónde enunciar nuestra palabra sin renunciar a la libertad.

Poder re-negar: sin embargo, la vida no se reduce a este estado, al ser víctima para siempre, y con la confianza en sí mismos podemos seguir en el mundo para poder ser otra vez de otra manera, tal como en el estado de abierto al cambio vislumbrado por la fenomenología, o en la búsqueda de sentido de la analítica existencial de Viktor Frankl.

La búsqueda de la vida misma, vivir sin rencor, sin cuentas por cobrar, o con ellas y dejarlas a un lado, ya es desvictimizarse; buscar el gusto en el estar, en el aquí, por lo vivido, o ver lo hermoso en lo pequeño; ver en el arte y en la espiritualidad caminos de superación de las 
miserias humanas — del mal con el que debemos habitar el mundo-, permite por fortuna, retomar las convicciones e ilusiones, volver a la lucha ética por una vida más digna y plural para re-negar de ese lugar de víctima asignada por el perpetrador y los indolentes.

Poder re-conocernos: esta renuncia a hablar desde el lugar de la víctima, traición para los institucionalizadores de la victimidad y la victimología, es poder renunciar a ser nombrado por otro como víctima, saberse sujeto de un daño que habita nuestro presente y pasado sin renunciar a la justicia y al derecho de vivir como la confianza fundamental de la vida lo manifiesta.

Poder re-corazonar (recordar sin rencor): no obstante, que del exilio nos queden los mejores recuerdos, pues re-cordar viene del corazón. La depuración de los vínculos, la purga de los amigos y familiares, las mejores enseñanzas del nuevo arraigo (re-arraigarse), y la fuerza que se multiplica a través de contundentes decisiones que nos permiten seguir mirando el por-venir.

Poder re-crearnos: hay que tomar la fuerza de la propulsión del exilio nómada, del desplazamiento forzado, ya como destierro al exterior o desplazamiento en el interior, dejarse llevar, convertirla en íntima aliada, aprovecharla, vivir la victimización y luego dejar de verse en el lugar de víctima para elevarse y ocupar un lugar diferente, una posición crítica, creativa y vital. Sabemos que esta no ha sido la vivencia y oportunidad de muchos que viven tal experiencia, pero es una opción que deberían tener en cuenta quienes han sido desacomodados violentamente en su forma de vivir.

Poder ayu-darnos: existe un mensaje propio que surge en lo más íntimo -tu primer hábitat, hogar, propiedad, fuerza y tierra en dónde habitar es tu sí mismo-, recorridos tus pasos sobre este camino con mayor serenidad puedes apoyar a quienes recién lo recorren.

Darnos en este proceso conlleva el valor y la fuerza para recorrer el camino que va del sufrimiento a la supervivencia, un trayecto en ascenso que pregunta desde la víctima: ¿cómo se aprovecha y reconecta el odio y el rencor en tanto sinapsis en la memoria social, como motor de la dignidad en la apuesta ética por la reconciliación? Para afrontar el nuevo reto que se despunta: ¿cómo desarticular el odio ilegítimo contra el ser humano, contra el semejante, que surge de la codicia y la ignorante negación de la diferencia? 



\section{Referencias}

Acevedo, Ó. (2011a). Entrevistas y notas de campo. Asociaciones de Víctimas del Oriente de Antioquia; Salón del Nunca Más, Granada-Antioquia.

Acevedo, Ó. (2011b). Geografías de la memoria: posiciones de las víctimas en Colombia en el periodo de justicia transicional 2005-2010. Bogotá. Ed. Universidad Javeriana.

Afavit. (2005). Asociación de familiares victimas en Trujillo, Valle. "IV Peregrinación a Trujillo- Afavit- y Comisión Intereclesial de Justicia y Paz". Comunicado público, 29 de mayo de 2005.

Aparicio, R. (2009). "La 'mejor esquina de Suramérica': aproximaciones etnográficas a la protección de la vida en Urabá". En: Colombia Revista de Antropología (Bogotá) ed: CINEP

Benjamin, W. (2008). Tesis sobre filosofía de la historia - aforismos. México. Itaca.

Benyakar, M. (2003). Lo disruptivo: amenazas individuales y colectivas. Argentina. Ed. Biblos.

Beristain, C. (2008) Las comisiones de la verdad en América Latina, una valoración de su impacto. El legado de verdad: Impacto de la Justicia transicional en la construcción de la democracia en América Latina. (p. 78). Bogotá. DFAE -Departamento Federal de Asuntos Exteriores de la Confederación Suiza-.

Beristain, C. (2009) Reconstruir el tejido social (p.69). Barcelona. Icaria. 
Cabildo Wayúu Nóüna. (2007). “Jain Tüu Wapushikat: Por el alma de nuestra gente" Consultar en. http://notiwayuu.blogspot.com.co/2007/04/jain-tuwapushikat-por-el-alma-de.html

Canclini, N. (1981). Una defininicón restringida de cultura. Cultura y sociedad: una introducción. México. Dirección General de Educación Indígena de la SEP México. Consultar en: https://es.scribd.com/doc/57587395/ canclini-Una-definicion-restringida-de-cultura

CARE. (2007). Centro de Acercamiento para la Reconciliación y la Reparación, San Carlos, Antioquia. Publicado y consultado en: http://www.centrodememoriahistorica.gov.co/multimedias/MemoriasExpresivasRecientes/ Memoria_H/antioquia/mapas/index.html.

Consejo Comunitario de Curvaradó. Iniciativa de memoria, peregrinación. Consultar en: http://www.centrodememoriahistorica.gov.co/multimedias/MemoriasExpresivasRecientes/Memoria_H/choco/nuevoregreso/ index.html

Consejo Comunitario del Río Naya. (2007). Conmemoración Crímenes de Lesa Humanidad en el Bajo Naya. Consultar en: http://justiciaypazcolombia.com/Conmemoracion-Crimenes-de-Lesa

Das, V. (2008). Sujetos del dolor, agentes de dignidad. Bogotá. Ed. Universidad Nacional de Colombia.

De Greiff, P. (2008). La contribución de la justicia transicional a la construcción y consolidación de la democracia. El legado de verdad: Impacto de la Justicia transicional en la construcción de la democracia en América Latina. Bogotá. DFAE -Departamento Federal de Asuntos Exteriores de la Confederación Suiza-.

Foucault, M. (1985). "La función política del intelectual: respuesta a una cuestión”. En: Saber y verdad. Madrid. Ed. La Piqueta.

Foucault, M. (1990). Las tecnologías del yo. Barcelona. Ediciones Paidós.

Foucault, M. (1999). ¿Qué es la ilustración? En: Estética, ética y hermenéutica. Barcelona. Paidós.

Foucault, M. (2007). La arqueología del saber., México. Fondo de Cultura Económica.

Giraldo, J. (2004). Búsqueda de verdad y justicia: seis experiencias en posconflicto. Bogotá. CINEP.

Gramsci, A. (1999). Antología. México. Siglo Veintiuno Editores.

Guattari, F. (1990). Las tres ecologías. Valencia. Pre-textos. 
Hall, S. (2010). Sin garantías: trayectorias y problemáticas en estudios culturales. Popayán. Envión Editores.

Han, B. (2015). Psicopolítica: neoliberalismo y nuevas técnicas de poder. México. Herder Editorial.

Kankuamos. (2007). Reencuentro con la memoria y los ancestros. Evento de memoria. Consultar en: http://prensarural.org/spip/spip.php?article411. Consultado: 15 de septiembre de 2015

Levinas, E. (1993). Entre nosotros: ensayos para pensar en otro. España. Pre-textos.

Malinowski, B. (1985). Crimen y costumbre en la sociedad salvaje. Barcelona. Planeta-agostini.

Mate, R. (2006). Contra lo políticamente correcto: Política, Memoria y Justicia. Buenos Aires. Altamira.

Mate, R. (2008). Justicia de las víctimas: Terrorismo, memoria, reconciliación. Barcelona. Anthropos.

Orozco, I. (2005). Sobre los limites de la conciencia humanitaria: Dilemas de la paz y la justicia en América Latina. Bogotá. Temis.

Peregrino, P. (2011). Fragmentos sobre guerra y paz. (S,c.) (S,e).

Provisames.(2007). Promotoras de vida y salud mental. Antioquia. Testimonios. (Notas de campo).

Quintero de Turbay. (2011)."Solo Escobar es responsable por la muerte de Diana”. Consultar en: http://m.eltiempo.com/buscador/MAM-4359085/1

Reátegui, F.(2007). El mosaico de la memoria: experiencias locales, no oficiales o parciales de búsqueda de la verdad histórica. Bogotá. Ed. ICTJ -Centro Internacional para la Justicia Transicional- y Fundación Social.

Ricoeur, P. (2000). Histoire et mémoire: l'écriture de l'historie et la répresentation du passe. Publicado en Revista Annles. Historie, Sciences Sociales. Núm. 55-4. (Julio-agosto de 2000). París.

Uprimny y Saffon. (2006). ¿Justicia transicional sin transición? Verdad, justicia y reparación para Colombia. Bogotá. Ed. Centro de Estudios de Derecho, Justicia y Sociedad.

San José de Apartadó. (2007). Comunidad de paz. Antioquia. Comunicado. Consultar en: http://www.derechos.org/nizkor/colombia/doc/vida.html. 



\section{Bibliografía contextual}

Acevedo, Ó. (2016). El corazón de las víctimas: aportes a la verdad y la reconciliación. Bogotá. Ed. San Pablo.

Hechos del callejón No. 21, 13, 26, 25, 23, 6, 14, 16, 20, 19, 18, 17, 15, 12. Bogotá. Acción Social.

Agacinski, S. (2009). El Pasaje: Tiempo, Modernidad y Nostalgia. Buenos Aires. La Marca Editora.

Aguilera, M. (2010). Las FARC: La Guerra Campesina, 1949-2010 خIdeas circulares en un mundo combatiente? Bogotá. ARF.

Ambos, K. (2010). Procedimiento de la Ley de Justicia y Paz (Ley 975 de 2005) y Derecho Penal Internacional. Bogotá. Temis.

Ambos, K.; Malarino, E. \& Elsner, G. (2009). Justicia de Transición: informes de América Latina, Alemania, Italia y España. Uruguay. Fundación Konrad-Adenauer.

Araújo, L. (1997). Seres con tiempo y con memoria. Formación Social Campesina. Bogotá. Resiembra. CINEP.

Araújo, L. (2004). Momentos en un camino hacia tu interior. Escuela Campesina de Desarrollo Humano Sostenible para la Convivencia y la Democracia. Bogotá. CINEP.

Arenas, M. (1999). Cerrando fronteras: Historias Contadas del Magdalena Medio. Programa de Desarrollo y Paz del Magdalena Medio. Barrancabermeja 
Arias, F. J. (ed.). (2008). Sin rastro, imágenes para construir memoria. Bogotá. Concurso Nacional de Fotografía sobre Desaparición Forzada. Fundación Dos Mundos.

Arias, F. J. (2009). Cuentos para no olvidar el rastro. Bogotá. Fundación Dos Mundos.

Atehortúa, A. (1995). El poder y la sangre: las historias de Trujillo (Valle). Bogotá. CINEP.

Avelar, I. (2000). Alegorías de la derrota: La ficción posdictatorial y el trabajo del duelo. Chile. Cuarto Propio.

Barrero, E. (2008). De Macondo a Mancuso: Conflicto, violencia politica y guerra psicológica en Colombia. Bogotá. Alternativa Gráfica.

Bauman, Z. (1999). La Globalización: consecuencias humanas. Buenos Aires. Fondo de Cultura Económica.

Bauman, Z. (2003). Comunidad: En busca de seguridad en un mundo hostil. Siglo xxi. España.

Bedoya, D. \& Jaramillo, J. (1991). De la barra a la banda: estudio analítico de la violencia juvenil en Medellín. Medellín. El Propio Bolsillo.

Belay, R.; Bracamonte, J.; Degregori, C. I. \& JoinvilleVacher, J. (ed.). (2004). Memorias en conflicto: Aspectos de la violencia política contemporánea. Lima. IEP Instituto de Estudios Peruanos.

Blair, E. (1999). Conflicto armado y militares en Colombia: Cultos, símbolos e imaginarios. Medellín: Instituto de Estudios Políticos. Universidad de Antioquia. CINEP.

Blair, E.; Pimienta, A. \& Gómez, S. (2003). Las imágenes del "otro” en las violencia(as) Colombia(nas) (Informe final de investigación). Medellín. INER. Universidad de Antioquia.

Blair, E.; Quiceno, N.; De Los Ríos, I. C.; Muñoz, A. M. \& Grisales, M. (2007). El derecho al pasado: Memoria para volver a vivir. Medellín. Universidad de Antioquia. Instituto de Estudios Regionales (INER)

Bleeker, M. (ed.). (2008). El legado de la verdad: Impacto de la justicia transicional en la construcción de la democracia en América Latina. Centro Internacional para la Justicia Transicional.

Bleeker, M. (ed.). (2008). El legado de la verdad: Impacto de la justicia transicional en la construcción de la democracia en América Latina (3B). Bogotá. Centro Internacional para la Justicia Transicional. 
Bobbio, N. (1993). Igualdad y libertad. Barcelona. Paidós Ibérica.

Bolívar, I. J. (2006). Discursos emocionales y experiencia de la política: Las FARC y las AUC en los procesos de negociación del conflicto (19982005). Bogotá. CESO. Universidad de los Andes.

Caballero, E. (1987). Memorias infantiles. Bogotá. Neira Impresiones.

Calveiro, P. (2005). Política y/o Violencia: Una aproximación a la guerrilla de los años 70. Argentina. Norma.

Canclini, N. (1999). La Globalización imaginada. Argentina. Paidós.

Castillejo, A. (2000). La poética del otro: para una antropología de la guerra, la soledad y exilio interno en Colombia. Bogotá. Instituto Colombiano de Antropología e Historia.

Cepeda, M. (1996). La memoria frente a los crímenes de lesa humanidad. Bogotá. Fundación Manuel Cepeda Vargas y Defensoría del pueblo.

Civico, A. (2009). Las guerras de "Doblecero”. Bogotá. Intermedio.

Comisión Nacional de Reparación y Reconciliación. (2007). Plan de acción 2007-2008.

Comisión Nacional de Reparación y Reconciliación. (2010). Boletín No. 13. Bogotá.

Colombia Nunca Más. (2000). Crímenes de lesa humanidad en la zona 14a, Tomo I. Bogotá. Corporación Colectivo de Abogados "José Alvear Restrepo.”

Colombia Nunca Más. (2000). Crímenes de lesa humanidad en la zona 14, Tomo II. Bogotá. Corporación Colectivo de Abogados "José Alvear Restrepo."

Colombia Nunca Más. (2008). Crímenes de lesa humanidad en la zona quinta. Bogotá. Corporación Colectivo de Abogados “José Alvear Restrepo.”

Colorado, J. (2005). Contra el Olvido en el Simposio Internacional de Justicia Restaurativa y Paz en Colombia. Simposio llevado a cabo en Cali.

Corporación Colectivo de Abogados "José Alvear Restrepo". (2008). Justicia para la justicia: El caso de la masacre de la Rochela Vs. Colombia, sentencia de 11 de mayo de 2007. Bogotá. Corporación Colectivo de Abogados “José Alvear Restrepo".

Corte Suprema de Justicia de Colombia. (2008). La protección de los derechos humanos a través de la jurisprudencia penal. Bogotá. Centro Internacional para la Justicia Transicional (ICTJ). 
Cortés, C. E. (ed.). (2006). Desaparición forzada, politica criminal y procesos restaurativos. Bogotá. Editora Géminis.

Cortés, H. (2005). i...Y el hombre negro también...! Pereira. Editorial Papiro.

Da Silva Catela, L. \& Jelin, E. (comp.). (2002). Los archivos de la represión: Documentos, memoria y verdad. Madrid. Siglo xxi Editores.

Daza, A. (comp.). (2001). Experiencias de intervención en conflicto urbano. Tomo I. Medellín. Alcaldía de Medellín.

Daza, A. (comp.). (2001). Experiencias de intervención en conflicto urbano. Tomo II. Medellín. Alcaldía de Medellín.

Debord, G. (2001). Consideraciones sobre el asesinato de Gérard Lebovici. Barcelona: Anagrama.

Degregori, C. I. (ed.). (2003). Jamás tan cerca arremetió lo lejos: memoria y violencia en Perú. Lima. IEP Instituto de Estudios Peruanos.

Delgado, A. C. (comp.). (2006). La Resilencia: desvictimizar la víctima. Bogotá. Feriva.

Díaz Gómez, C. (ed.). 2008. Reparaciones para las víctimas de la violencia política: Estudios de caso y análisis comparado. Bogotá. Centro Internacional para la Justicia Transicional.

Díaz Gómez, C.; Sánchez, C. N. \& Uprimny Yepes, R. (2009). Reparar en Colombia: los dilemas en contextos de conflicto, pobreza y exclusión. Bogotá. Centro Internacional para la Justicia Transicional.

Díaz Montealegre, G. (coord.). (2009). De nuestras voces: memorias para un nuevo caminar. Bogotá. Hijos e hijas por la memoria y contra la impunidad.

Ejercito Nacional de Colombia. (1997). Infracciones graves al derecho internacional humanitario, violaciones a los derechos bumanos y crimenes de lesa humanidad consumados por organizaciones narcoterroristas en la jurisdicción de la quinta división del Ejercito Nacional de Colombia. Bogotá. Quinta División del Ejército.

Estrada, W. \& Gómez, A. (comp.). (1992). Somos historia: Comuna Nororiental. Medellín.

Fentress, J. \& Wickham, C. (2003). Memoria Social. Madrid. Ediciones Cátedra.

Fundación Alvaralice. (2006). Sanar, no tanto castigar. Cali. Simposio Internacional de Justicia Restaurativa y Paz en Colombia. 
Garay Álvarez, A. (2008). Memoria de Caín: los poemas del purgatorio. Bogotá .Corporación Unificada Nacional de Educación Superior.

Ginzburg, C. (1991). El juez y el historiador: Consideraciones al margen del proceso Sofri. Madrid. Anaya.

Gómez Aristizábal, H. (1990). Las pruebas en el Nuevo Procedimiento Penal. Bogotá. Tercer Mundo Editores.

Gómez Aristizabal, H. (1990). Normas Básicas de Procedimiento Penal. Bogotá. Tercer mundo editores.

Gómez Méndez, M. P (comp.). (2007). El mosaico de la memoria: Experiencias locales, no oficiales o parciales de búsqueda de la verdad histórica. Bogotá. Centro Internacional para la Justicia Transicional.

Habermas, J. (1999). La inclusión del Otro: Estudios de Teoría Política. Buenos Aires. Paidos.

Herrán, M. T.; Losada, D. \& Guerrero, A. (2005). Cubrimiento periodístico responsable del desplazamiento forzado interno. Bogotá. Medios para la Paz MPP.

Humanidad Vigente-Corporación Jurídica. La estrategia de la memoria. Una propuesta de recuperación de memoria de crímenes de lesa humanidad y lucha contra la impunidad.

Humanidad Vigente-Corporación Jurídica. (2007). Memorias de la represión. Persecusión al movimiento estudiantil en el Departamento de Nariño. Bogotá. Humanidad Vigente-Corporación Jurídica.

Humanidad Vigente-Corporación Jurídica. (2007). Operación relámpago: crimenes de lesa humanidad contra "A Luchar" en el Valle del Cauca.

Humanidad Vigente-Corporación Jurídica. (2007). Recuperación de tierras crimenes de lesa humanidad en el resguardo de Tuquerres. Bogotá. Humanidad Vigente-Corporación Jurídica.

Hurtado Hurtado, L. E. (2001). Un modelo teórico para una teoría procesal de la paz. (Tesis de especialización en Derecho Constitucional). Universidad de Antioquia. Medellín.

Instituto Interamericano de Derechos Humanos. (2006). Atención integral a víctimas de violaciones graves a los derechos humanos. Bogotá. Taller Psicojurídico.

Instituto Interamericano de Derechos Humanos. (2008). Derechos humanos $y$ derechos de los afrodescendientes elementos básicos de derechos humanos: guía introductoria. Costa Rica. Editorama. 
Instituto Popular de Capacitación IPC. (2001). Movimiento Social por la Paz y Hermanamientos: Pueblos Hermanos... Lazos Visibles. Medellín.

Instituto Popular de Capacitación. (2006). Píldoras para la memoria: violaciones de Derechos Humanos y crimenes de lesa humanidad en el Valle de Aburrá y el Oriente antioqueño (2000-2004). Medellín. Instituto Popular de Capacitación.

Jaspers, K. (1998). El problema de la culpa: sobre la responsabilidad política de Alemania. Barcelona. Paidós.

Juliá Santos (coord.). (1999). España. Víctimas de la guerra civil. Lável.

Krotz, E. (ed.). (2002). Antropología Jurídica: Perspectivas socioculturales en el estudio del derecho. México. Anthropos.

La Capra Dominique. (2005). Escribir la historia y el trauma. Buenos Aires. Ediciones Nueva Visión.

Lancheros Ruíz, A.C. \& Rincón Ortiz, J. A. (2006). Bojayá: entre el miedo $y$ los medios. (Premio Nacional de Periodismo). Universidad Externado de Colombia. Bogotá.

Lefranc, S. (2005). Políticas del perdón. Bogotá. Editorial Norma.

Linares Prieto, P. (coord.). (2009). Construcción de memoria, estado y medios. Secretaría General Alcaldía Mayor de Bogotá.

Linares Prieto, P. (coord.). (2009). Diez años de políticas públicas de atención a desplazados en Bogotá. Secretaría General Alcaldía Mayor de Bogotá.

Linares Prieto, P. (coord.). (2009). La construcción del contexto y la metodología para el estudio de caso. Secretaría General Alcaldía Mayor de Bogotá.

Linares Prieto, P. (coord.). (2009). Protección de la memoria: legislación, jurisprudencia y doctrina. Secretaría General Alcaldía Mayor de Bogotá

Londoño, L. M. \& Ruiz, A. (2010). Desde diversas orillas: Manual para uso pedagógico. Medellín. Universidad de Antioquia. INER.

López Restrepo, A. (ed.). (2008). Análisis Político. Revista del Instituto de Estudios Políticos y Relaciones Internacionales. Bogotá. Universidad Nacional de Colombia.

Madin, E.; Mate, R.; Mayorga, J.; Rubio, M. \& Zamora, J. A. (2008). El perdón, virtud política: en torno a Primo Levi. Barcelona. Anthropos.

Magil, M.G. (2008). Crónica oculta del conflicto: Estrategias de impunidad en la narcopolítica, el acuerdo humanitario, los desaparecidos... y el fin de la guerra. Bogotá. Ediciones desde abajo. 
Marín Ortíz, I. (2009). Los retos de la Justicia Transicional en Colombia: percepciones, opiniones y experiencias 2008. Bogotá. Fundación Social.

Medina Doménech, R. M; Molina Rueda, B. \& García-Miguel, M. (eds.). (2008). Memoria y reconstrucción de la paz: enfoques multidisciplinares en contextos mundiales. Madrid. Universidad de Granada.

Müller, H. (2009). En tierras bajas. Santillana.

Naranjo, J. (comp.). (2007). Me gustaba mucho tu sonrisa. Medellín. Alcaldía de Medellín.

Nieto Sua, L. D. (comp.). (2012). Desafíos para la reparación integral a la víctimas del conflicto armado interno en Colombia. Memorias del Seminario Internacional. Alcaldía Mayor de Bogotá.

Nieto, P. (comp.). (2007). El cielo no me abandona. Medellín. Alcaldía de Medellín.

Nieto, P. \& Betancur, J. M. (comps.). (2006). Jamás olvidaré tu nombre. Medellín. Alcaldía de Medellín.

Orozco Abad, I. (2009). Justicia Transicional en tiempos del deber de memoria. Bogotá. Temis.

Ortega, F. A. (2008). Venna Das: Sujetos de dolor, agentes de dignidad. Bogotá. Universidad Nacional de Colombia.

Ortiz Palacios, I. D. (2008). Jaime Pardo Leal: Patriota de la Unidad. Bogotá. Barrancabermeja. Universidad Nacional de Colombia.

Osten, M. (2008). La Memoria robada: sistemas digitales y deconstrcción de la cultura del recuerdo. España. Siruela.

Pacheco Osorio, P. (1972). Derecho Penal Especial. Bogotá. Temis.

Papacchini, A. (1994). Filosofías y derechos humanos. Cali. Universidad del Valle.

Peñaranda Supelano, D. R. (2010). El movimiento armado Quintín Lame (MAQL): Una guerra dentro de otra guerra. Bogotá. ARFO.

Pereyra, C.; Villoro, L.; González, L.; Blanco, J. J.; Florescano, E.; Córdova, A.; Aguilar Camín, H.; Monsiváis, C.; Gilly, A. \& Bonfil Batalla, G. (1980). Historia ¿Para qué? México. Siglo xxi editores.

Pérez-Sales, P. \& Navarro García, S. (2007). Resistencias contra el olvido: Trabajo psicosocial en procesos de exhumaciones. Barcelona. Gedisa. 
Portilla Benavidez, A.C. (2003). Comisiones de la verdad en América Latina: Un instrumento necesario pero no suficiente. (Tesis de grado). Universidad Externado. Bogotá.

Procuraduría Delegada para la Prevención en materia de Derechos Humanos y Asuntos Étnicos. (2008). Protección y garantía del derecho a la propiedad y a las posesiones de las víctimas del conflicto armado interno. Bogotá. Procuraduría General de la Nación.

Programa Presidencial de Derechos Humanos y DIH. (2008). Voces contra el olvido: Reconstrucción del caso de la masacre de la Rochela. Bogotá. Presidencia de la República.

Reátegui Carrillo, F. (2006). Iniciativas de búsqueda de la verdad en Colombia: una visión panorámica. Bogotá. Fundación Social.

Red Juvenil de Medellín. (2008). Los sueños de los jóvenes no se pueden camuflar: Informe de Derechos Humanos 2007. Medellín. Red Juvenil de Medellín.

Reed Hurtado, M. (Ed.). (2008). Judicialización de crímenes de sistema. Bogotá. Centro Internacional para la Justicia Transicional.

Reiniciar. (2006). Tejiendo la memoria de una esperanza: Unión Patriótica. Bogotá. Corporación para la Defensa y Promoción de los Derechos Humanos.

Restrepo Restrepo, A. \& Contreras Rodríguez, M. (2000). Flor de Abril: la corriente de Renovación Socialista, de las armas a la lucha política legal. Bogotá. Corporación Nuevo Arco Iris.

Riaño Alcalá, P.; Lazy, S. \& Agudelo Hernández, O. C. (2003). Arte, Memoria y Violencia: Reflexiones sobre la ciudad. Medellín. Pregón.

Richard, N. (2007). Fracturas de la memoria. Argentina. Siglo xxI Editores.

Richard, N. \& Moreiras, A. (eds.). (2001). Pensar en/la posdictadura. Chile. Editorial Cuarto Propio.

Rodríguez Idárraga, N. (2008). Los vehículos de la memoria: discursos morales durante la primera fase de la violencia (1946-1953). Bogotá. Uniandes - CESO. Universidad de los Andes.

Rodríguez, A. R. (2006). Proyecto de vida: sistematización 2006. Medellín. Corporación Empresarial del Oriente Antioqueño CEO, Fundación para el Desarrollo Humano FBH.

Romero, M. (2008). Verdad, memoria y reconstrucción. Bogotá. Centro Internacional para la Justicia Transicional. 
Rosero, E. (2006). Los ejércitos. Barcelona. Tusquets.

Rottberg, A. (2008). Reparación en Colombia ¿Qué quieren las víctimas? Bogotá. Agencia GTZ.

Rubio, M. (1999). Crimen e impunidad: precisiones sobre la violencia. Bogotá. TM Editores.

s. a. (1985). Libro negro sobre Colombia. Editorial Andina S.A. Bogotá.

Sánchez Gómez, G. (Coord.). (2008). Narrativas y voces del conflicto: Plan de investigación. Grupo de Memoria Histórica-CNRR.

Sánchez Gómez, G. (Coord.). (2008). Trujillo: una tragedia que no cesa. Bogotá. Grupo de Memoria Histórica.

Sánchez Gómez, G. (Coord.). (2009). Recordar y narrar el conflicto: herramientas para reconstruir memoria histórica. Bogotá. Grupo de Memoria Histórica-CNRR.

Sánchez, G. (Coord.). (2009). La masacre del salado: Esa guerra no era nuestra. Bogotá. Taurus.

Sánchez, G. (Coord). (2010). Una historia de paz para contar, recontar y no olvidar. Bogotá. Memoria Histórica.

Sánchez, G. (Coord.). (2011). El orden desarmado: La resistencia de la Asociación de Trabajadores Campesinos del Carare (ATCC). Bogotá. Taurus.

Sánchez, G. (Coord.). (2011). La masacre de El Tigre Putumayo. Bogotá. Pro-offset Editorial.

Sánchez, G. (Coord.). (2011). La memoria histórica desde la perspectiva de género. Bogotá. Pro-offset Editorial.

Sánchez, G. (Coord.). (2010). Bojayá: La guerra sin límites. Bogotá. Taurus.

Sánchez, G. (2011). San Carlos: Memorias del éxodo en la guerra. Bogotá. Taurus.

Serna Dimas, A. (comp.). (2009). Memorias en Crisoles: propuestas teóricas, metodológicas y estratégicas para los estudios de la memoria. Bogotá. Universidad Distrital Francisco José de Caldas.

Tamayo, G. (2008). La aldea de las hadas y los héroes. Medellín. Prográficas.

Torres, M. (2010). La siempreviva. Medellín. Tragaluz Editores.

Touraine, A. (1997). ¿Podremos vivir juntos? Argentina. Fondo de Cultura Económica. 
Tovar Pinzón, H. (2009). Los fantasmas de la memoria: Poder e inhibición en la historia de América Latina. Bogotá. Universidad de Los Andes.

Unión Europea. (2007). Directrices en Materia de Derechos Humanos. Bogotá. Delegación de la Comisión Europea para Colombia y Ecuador.

Uribe Alarcón, M. V. (2004). Antropología de la Inhumanidad. Bogotá. Norma.

Uribe Alarcón, M. V. (2007). Salvo el poder todo es ilusión. Mitos de origen: Tigres Tamiles de Sri Lanka, Fuerzas Armadas Revolucionarias de Colombia, Irish Republican Armi. Bogotá. Instituto Pensar. Pontificia Universidad Javeriana.

Uribe, A. (2005). El Fantasma Pinochet. España. Galaxia Gutenberg.

Vial, G. (ed.). (1998). Análisis crítico del régimen militar. Chile. Universidad Finis Terrae.

Vieira, G. (2000). Liderazgo para el desarrollo sostenible en América Latina. Chile. Avina.

Villa Gómez, J. D.; Tejada Bermúdez, C.; Sánchez Benítez, N. \& Téllez Luque, A. M. (2007). Nombrar lo Innombrable: Reconciliación desde la perspectiva de las víctimas. Bogotá. Panamericana Formas e Impresos.

Villarraga Sarmiento, Á. (ed.). (2006). La reinserción en Colombia: Experiencias, crisis humanitaria y política pública. Bogotá. FUCUDE.

Worden, J. W. (1997). Tratamiento del duelo: Asesoramiento psicológico y terapia. España. Paidós.

Ysern de Arce, J. L. (1990). Verdad y Justicia: el desafío del reencuentro.

Chile. CESOC Ediciones ChileAmérica.

Yusti, M. R. (1999). Escuela y desplazamiento, "una propuesta pedagógica". Bogotá. Ministerio de Educación Nacional. 



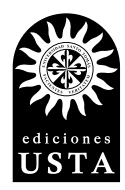

Esta obra se editó en Ediciones USTA,

Departamento Editorial de la Universidad Santo Tomás.

Se usó papel propalcote de 300 gramos para la carátula y papel bond beige de 75 gramos para páginas internas.

Tipografía de la familia Sabón. Impreso por Grupo Dao Digital S.A.S. 2017. 
¿En dónde comienza el tratamiento y la intervención a las víctimas? ¿En las metodologías de acompañamiento o en las teorías e ideas que dan origen a estas? En torno a esta reflexión gira Episteme de la victimidad como un análisis amplio sobre la producción de la victimología y el discurso sobre las víctimas; a manera de una metavictimología que se interroga por el origen de los discursos y prácticas que intervienen a las víctimas del conflicto armado. Esta apuesta conceptual reclasifica la lógica de la victimización al diferenciar la sujeción al daño según sea la condición de la víctima sufriente, sobreviviente y superviviente de acuerdo con su posición frente a los perjuicios vividos.

De igual manera Episteme de la victimidad delibera en torno a una ecosofía del daño y sobre las consecuencias de los discursos expertos así como del rol de los socorristas del daño; sobre cómo expertos y socorristas pueden aportar no solo a la reparación legal sino también al proceso de reposicionamiento y paso psicojurídico del sufriente a sobreviviente, y en la apuesta psicopolítica del superviviente. Para ello, el trabajo sobre la memoria histórica, diferenciada aquí en sus acepciones de memoria reparativa y memoria restaurativa, se presenta como un macroartefacto de producción de resignificación que apoya los procesos subjetivos en el tránsito del sufriente a sobreviviente y a superviviente, teniendo una teleología explicita: el horizonte de la desvictimización.

Esta formulación conceptual, que de igual manera deriva como un marco de la investigación "Diseño de un modelo de acompañamiento y peritaje psicosocial con enfoque psicojurídico y diferencial en casos de violaciones de los derechos humanos” de la Maestría en Psicología Jurídica de la Universidad Santo Tomás se concreta en una invitación pedagógica para el fomento de la paz, la convivencia y la reconciliación, en el "TAYER Hoy", un conjunto de estrategias y actividades lúdico-reflexivas que sirven de apoyo al proceso de elaboración de la memoria social bajo la modalidad de memoria restaurativa.

Con estas tareas conceptuales, metodológicas y subjetivas se ha compuesto el libro que tiene en sus manos: Episteme de la victimidad: Reposicionar al sobreviviente y reparar a la víctima. 